\title{
Rosa Sanmartín Pérez, La labor dramática de Manuel y Antonio Machado, Granada, Ediciones Mágina, Editorial Octaedro Andalucía, 2010, 220 pp.
}

Se trata de un libro particularmente estimado y hasta diría que nostálgico para mí, puesto que enfoca un asunto del que me vengo ocupando desde 1970; es decir, hace más de cuarenta años. Fue entonces cuando comencé mi memoria de licenciatura, bajo la dirección del doctor Orozco Díaz, catedrático de la Universidad de Granada, que hizo que me interesara por el teatro machadiano cuando todavía nadie se ocupaba de ese asunto, pues no existía sobre él más que en el espléndido artículo de Eusebio García Luengo en Cuadernos hispanoamericanos XI-XII, de 1949, y posteriormente el libro de Manuel H. Guerra de 1966, que llegó a mis manos cuando tenía muy avanzado el estudio. Aquel primer trabajo, que constituía mi memoria de licenciatura (La obra dramática de Manuel y Antonio Machado, Universidad de Granada, 1971) poseía tan inusual extensión (dos volúmenes, 1005 páginas), que tuve que justificarlo por consejo de Orozco en el prólogo, porque incluso para lo que entonces "se estilaba" parecía excesiva extensión. Así constaba: “Queremos desde un principio curarnos en salud respecto a la extensión de esta obra, anormal para una memoria de licenciatura; pero creemos firmemente que si este estudio es un acopio de material en su mayor parte inédito, no podía ser de otra manera. Además, los años de las síntesis no son precisamente los juveniles y debemos estar de acuerdo con nuestra edad (22 años): ahora se impone el analizar, pensar e investigar para llegar con el tiempo a conclusiones válidas que puedan incluirse en sólo dos líneas de un libro".

De ese trabajo de 1971 fueron surgiendo sucesivas publicaciones, comenzando por la misma tesis doctoral (En el contexto de teatro en verso: los Machado y Ángel Lázaro. Un intento de aproximación a través de la crítica), defendida en la misma universidad granadina en 1975 y cuyo resumen aparecía como publicación en 1976, además de otros estudios que culminaron en la edición de todas las obras teatrales machadianas, la última de las cuales (El hombre que murió en la guerra) ha aparecido en EspasaCalpe, $\mathrm{n}^{\circ} 624$ de la Colección Austral, Madrid, 2008. Por eso el ver ahora un libro de asunto e incluso de título tan similar, escrito por persona joven y con idéntico ímpetu, transcurridos cuarenta años, me llena de nostalgia y me permite, siquiera por breve tiempo, adentrarme de nuevo en un asunto que me fue y es particularmente querido. Únese a ello el formado parte del tribunal que juzgó y calificó la tesis doctoral de la profesora Rosa Sanmartín, que defendió con absoluto éxito en la Universidad de Valencia hace un par de años.

La profesora Rosa Sanmartín Pérez nació en Valencia en 1974 y es, como acabo de decir, doctora en Filología Hispánica por aquella universidad. Es colaboradora en el servidor web de literatura española Parnaseo y coordinadora de la revista electrónica Stichomythia. Es coautora de diversas publicaciones, entre las que destacan Lineas actuales de investigación literaria, de 2004, ¿De qué se venga Don Mendo?: 
Teatro e intelectualidad en el primer tercio del siglo XX, también de 2004, y Campus stellae. Haciendo camino en la investigación literaria, de 2006. Ha publicado en diversas revistas y participado en numerosos congresos sobre literatura española.

La obra que pretendo enjuiciar consta de dos partes netamente diferenciadas: la primera es un estudio profundo y completo de toda la teoría dramática de los Machado y en particular del conocido como Manifiesto teatral de ambos hermanos (1928-1941), que constituye a mi juicio el trabajo más completo que conozco sobre este asunto y que pone en claro una serie de datos que hasta ahora desconocíamos. Evidentemente, la prensa fue receptora de toda la teoría teatral de los Machado, tanto de Antonio como de Manuel. Este último fue, como es sabido, crítico profesional en ejercicio primero en El Liberal y luego en La Libertad; y Antonio, aunque no de manera tan asidua, fue publicando trabajos sobre teatro, que comienzan sin duda por un estudio de gran interés y al cabo de mayor trascendencia. Se trata del artículo Sobre el porvenir del teatro, publicado por primera vez en Segovia, en abril de 1928, en la revista Manantial y, unos días más tarde, el 27 del mismo mes, en la revista La Libertad. Este texto, que constituye la base del conocido hoy como Manifiesto, aparece, pues, publicado bajo la firma del menor de los hermanos, aunque luego se reconoce como depositario de la ideología de ambos acerca del teatro.

El trabajo de Rosa Sanmartín nos permite adentrarnos con toda suerte de detalles en el estudio de este texto y en otro más, aparecido precisamente en abril de 1928, unos días antes del estreno de Las adelfas en el teatro Eldorado de Barcelona, en que vuelven a publicar un texto referido a la creación dramática de ambos, en esta ocasión firmado por los dos. Es un artículo que aparenta una reseña del estreno de Las adelfas, pero que en realidad reproduce una entrevista que uno de los redactores de La Noche y El Día Gráfico, Francisco Madrid, había realizado a ambos hermanos. Hay, pues, una comunidad interesada de opiniones sobre teatro, fruto sin duda de la entrañable relación de ambos, que les hizo compartir hasta el mismo hecho de editar, actualizar y comentar sus propias obras dramáticas. Este capítulo debe tener para nosotros un valor singular, porque por primera vez aclara una serie de puntos que habían sido objeto de discusión de todos los críticos que nos hemos acercado al teatro machadiano, comenzando por Miguel Pérez Ferrero, que en su conocida Vida de Antonio Machado y Manuel había tratado con rigor -creíamos- suficiente aspectos del mismo como para quedar claramente informados del Manifiesto, aunque, transcurrido ya tanto tiempo, se observa una serie de deficiencias que en el libro de Rosa Sanmartín quedan definitivamente aclaradas.

Hay un segundo fragmento de este capítulo que merece particular elogio. Es el titulado La teoría teatral en su obra dramática, donde analiza y confirma cómo se va cumpliendo, adaptando y practicando toda esta teoría en su obra original, desde el primer drama (Desdichas de la fortuna o Julianillo Valcárcel, 1926) hasta el último (El hombre que murió en la guerra, 1941). En la primera obra ya se aprecia alguno de los rasgos más significativos de su teoría teatral, sobre todo cuando constatan y confirman por vía práctica que el teatro es un arte de tradición y de frutos tardíos, como decía Pidal, lo cual les lleva a tomar como modelo dramático lo más acendrado y novedoso 
de nuestro Siglo de Oro, ya que el drama se ambienta en la corte de Felipe IV y enfoca desde nueva perspectiva la historia del bastardo del Conde-Duque Julianillo Valcárcel.

El otro capítulo que nos merece particular atención y valoración es el referido a la última obra teatral de los Machado: El hombre que murió la guerra, estrenada en 1941, puesto que Las tardes de la Moncloa o las brujas de Don Francisco, La diosa razón y El loco amor son tres obras de las que tenemos diferentes noticias pero que nunca llegaron a representarse. El análisis de la profesora Sanmartín de esa última pieza representada nos parece de particular rigor y que supera con mucho los anteriores estudios sobre la misma, que han sido por cierto muy abundantes, hasta el punto de ser la que mayor número ha concitado en su torno, ya que la mayor parte de los estudiosos del teatro machadiano, comenzando por Miguel Ángel Baamonde, Jordi Doménech, Fatma Benhamamouche, etc., etc. hemos dedicado nuestra atención preferente a esta obra, atractiva como pocas en la dramaturgia del siglo XX. Tan significativa, distinta y sugerente es que ha venido despertando la atención de todos nosotros, que volvemos a ella una y otra vez; en mi caso desde 1971, en que le dedicaba ya un amplísimo capítulo (páginas 500 a 566) que el tribunal, presidido por Orozco, destacó sobremanera y que no he dejado de atenderla en los últimos cuarenta años, como hemos hecho todos cuantos nos acercamos al teatro machadiano, en especial Miguel Ángel Baamonde Hermida, que le dedicó casi todo su espléndido libro $\mathrm{La}$ vocación teatral de Antonio Machado (Madrid, Gredos, 1976). De estos reiterados trabajos puede verse un completo resumen en nuestro estudio introductorio a la edición de dicha obra, publicada conjuntamente con El aguilucho, de Edmond Rostand, en la Colección Austral de Espasa Calpe, Madrid, 2008. Pues bien, el trabajo de la profesora Sanmartín rehace y reformula en parte la opinión que defendía en su tesis doctoral, donde hablaba abiertamente de dos diferentes versiones de esta obra; una primera en dos actos, presentada a la censura bajo el nombre de Antonio Machado, y una segunda versión, en cuatro actos, añadida y firmada ahora por ambos hermanos. El libro que comentamos matiza en parte sus opiniones anteriores respecto a la autoría, que casi todos creíamos exclusiva de Antonio, pero queda clara la existencia de ambas versiones, aunque al final hayamos de concluir con la profesora Sanmartín que se trata de una obra también en colaboración, como todo el teatro suscrito por ambos. Queda clara, tras el pertinente estudio, la opinión de la autora, que le lleva a concluir que la obra se terminó de escribir en 1935 y que fue realizada en dos momentos bien diferenciados; el primero en 1929, en el cual quedarían concluidos los dos primeros actos, con temática bastante diferente al tercero y cuarto. De hecho -dice- a posteriori aparece un cuaderno de hule negro en el que se incluyen los actos tercero y cuarto de forma independiente de los anteriores, aunque a continuación de éstos, lo que viene a confirmar la sospecha -ya a casi certidumbre- de ambas versiones.

En opinión de la autora, perfectamente suscribible, los hermanos Machado innovaron y renovaron la escena española de su tiempo, aunque ello haya pasado desapercibido para la crítica posterior, que ha prestado atención a las nuevas corrientes teatrales del primer tercio del siglo XX y no ha terminado de entender el valor del teatro machadiano, que se esforzó por la recuperación de nuestra dramaturgia del Siglo de 
Oro, particularmente de Lope, coincidiendo con lo que opinábamos hace tantos años, cuando ya dedicamos un capítulo completo a la inserción del teatro machadiano en nuestra dramaturgia clásica; que produjo un nuevo tratamiento del Don Juan literario; que introdujo la psicología freudiana o la búsqueda del otro, temas -como dice- bien dibujados en la dramaturgia machadiana, en la que se unen tradición y leyenda, lo clásico y lo moderno y que consigue el logro personal de La Lola se va a los puertos, retrato de la cultura popular tan arraigada en ambos hermanos desde la infancia, y que se cierra con El hombre que murió la guerra, última del ciclo, de un amplio círculo que comenzó quince años atrás con Las adelfas. Rosa Sanmartín une estas dos obras porque, como puede comprobarse a lo largo de su estudio, ya estaba en la mente de los autores a la altura de 1928 la creación de esta última pieza, precisamente mientras la escribían, de la cual forma una especie de epígono, dato decisivo para entender el teatro de los Machado. Decía Manuel en una de sus crónicas que a pocos se les había ocurrido pensar que uno de los medios más eficaces para conjurar toda crisis comercial estriba en mejorar la mercancía, en dar buen género y en darlo barato, y que cuando tal sucede se produce inexorablemente el éxito, como sucedía cuando cantaba Fleta en el regio coliseo y éste se llenaba pese a lo elevado de los precios o cuando Lola Membrives representaba en el Lara, rebosante siempre de público, costase lo que costase. Por eso los Machado, cuando suben sus obras a la escena, lo hacen con las mejores compañías: María Guerrero, Lola Membrives, Irene López Heredia y con el mejor género: toda una tradición popular folclórica, que les viene desde la figura paterna, el primer folclorista, Demófilo, que ellos convertirán en dramática renovadora, en la que quedaron plasmadas las teorías teatrales de ambos autores y la necesidad de una regeneración teatral, tan comentada en el ámbito escénico de aquellos años.

Pero en la dramaturgia machadiana -concluye Rosa Sanmartín- "hay algo más de original y es el hecho de que los hermanos Machado hagan confluir historia y leyenda, tradición y modernidad. Los Machado, buenos conocedores de la tradición popular -de la que Manuel fue fiel reflejo en sus composiciones poéticas-, emplearon esta característica para crear obras nuevas; en ellas, la leyenda y la historia se mezclan con rasgos característicos de principios de siglo como el individualismo, las teorías freudianas, el subconsciente, la mujer la crítica burguesa...". La única excepción, pese a la abundancia de estudios y las dificultades de su interpretación, será El hombre que murió en la guerra, que ha sido estudiada con más ahínco que cualquiera otra de sus producciones.

La pregunta que formula y nos formulamos todos es la de siempre: ¿por qué esta falta de interés general por el teatro de los Machado? Está claro que todavía la obra dramática de ambos no ha alcanzado la altura de sus respectivas obras líricas; pero lo mismo sucedió con Valle-Inclán, del que hace cincuenta años nadie conocía nada de su obra teatral y ahora es uno de los grandes dramaturgos del siglo XX. Debemos creer, además, que este olvido se debe a la repercusión histórica de la figura de Antonio Machado o sencillamente a implicaciones políticas que no hay por qué recordar.

Ya en 1970 hablábamos por extenso de que se hacía necesario rescatar del oscuro fondo a los Machado y su teatro. Esto mismo se sigue pretendiendo a la altura de 2010. 
“Devolver- dice Rosa Sanmartín- si no a la escena española, sí a la memoria, una faceta de la historia del teatro poco recordada. Faceta que, azarosamente -añade ella- un poco como empezamos este trabajo, no llevó a descubrir, ya no en la prensa sino entre la censura que tanto daño hizo a la dramática de aquella época, un manuscrito de Antonio Machado que contenía la versión primera de El hombre que murió la guerra". Decía José Bergamín -apostilla- en un trabajo de 1975 que las cosas que no pasan deben valer para siempre y entre ellas habrá que citar a ambos hermanos, siempre inseparables en su creación dramática, por muy diferentes caminos que tomarán uno y otro. El unir ambos caminos para recobrar una creación conjunta ha sido la misión de este trabajo, que a nosotros nos ha agradado particularmente. La bibliografía que reúne es la mejor seleccionada y la más completa que hasta estos momentos se ha compuesto y recopilado, valga la paradoja; la mejor y más añadida, como se decía antes, del teatro machadiano.

Las mínimas deficiencias formales que encontramos en el estudio en nada empecen el valor del libro, porque hoy son ya tan frecuentes, que han quedado como asidero de viejos cascarrabias, que no transigimos todavía y nos resistimos como podemos con "la modernidad idiomática" que nos imponen las circunstancias y contra la que en balde nos rebelamos. Las cosas son como son y no como uno quiere que sean. Apenas vale la pena citar: algunas comas de más, algún anacoluto y alguna expresión no enteramente castellana, que son fruto o del tiempo que pasa o de nuestra incompetencia para enseñar a escribir incluso a los mejores alumnos. Por lo demás, el estudio constituye una interesante y más que valiosa aportación a un asunto que viene ocupando ya a muchos investigadores y cuyo comienzo por nuestra parte, recordado ahora con nostalgia, se remonta exactamente a cuarenta años atrás, en el otoño de 1970.

Dámaso Chicharro 